\title{
Teaching \& Learning for International Students in a 'Learning Community': Creating, Sharing and Building Knowledge
}

\author{
Linzi Kemp, PhD \\ Assistant Professor, Department of Management, Marketing \& Public Administration \\ American University of Sharjah \\ This article considers the culture of learning communities for effective teaching. A \\ learning community is defined here as an environment where learners are brought \\ together to share information, to learn from each other, and to create new \\ knowledge. The individual student develops her/his own learning by building on \\ learning from others. In a learning community approach to teaching, educators can \\ ensure that students gain workplace skills such as collaboration, creativity, critical \\ thinking, and problem solving. In this case study, it is shown how an active learning \\ community, introduced into a blended teaching environment (face-to-face and \\ virtual), effectively supported international undergraduates in the building of \\ knowledge and workplace skills.
}

This article considers the value of a learning community for the effective teaching of international students. Specifically, the learning community in this article included two sections of business undergraduates, enrolled in a junior-level elective course on Leadership at a university in the United Arab Emirates. The students participated in a blend of face-to-face (F2F) and online interactions. The rationale behind the inception of a learning community approach to teaching was to increase students' ability to create, share, and build knowledge together. The article aims to help educators understand how the creation of a learning community composed of students of different nationalities can be a more effective teaching methodology than traditional teaching. Although this teaching location is outside of the United States of America, the material in the article is of value for multicultural classrooms worldwide.

\section{Learning Community - Definition}

The formal definition of learning community begins with Tinto's (2003) observation that students are usually "watchers" in class, listening passively as the teacher talks. Tinto (2003) was concerned about the disconnect that ensued for students: disconnect between students and the institution, and disconnection between students and their learning. Passive listening causes disconnection because students are not able, nor are they led, to make connections in their learning across the curriculum. Furthermore, disconnect can happen as students passively accept information rather than actively apply it to the practical world of employment. These

\author{
Passive listening causes \\ disconnection because \\ students are not able, nor \\ are they led, to make \\ connections in their learning \\ across the curriculum.
} disconnections can lead to student failure in individual courses, and a failure to retain those students to degree success. In Tinto's (2003) opinion, a restructuring of learning is necessary to increase students' connection with each other for each student to become a resource for others. Furthermore, connection between the student and the institution is necessary to gain maximum learning potential from other resources; examples would be the library, other professors, and writing centers. Knowledge would flow more effectively, according to Tinto (2003), if a new 
model of teaching and learning was introduced "that enables students to take courses together, rather than apart" (p. 1). This theme of connection is followed by Gabelnick et al. (1990), when they consider that a learning community is very much about deliberately putting students in a relationship with other students in courses. Price (2005) maintains the idea of relationship building when proposing that small groups of college students can be kept together as a cohort while they are studying. A consideration then is that in the classroom it is important to connect students with each other and to resources.

Tinto and Goodsell-Love (1993) studied first-year students in three collaborative learning programs in the United States. Through quantitative and qualitative research methodology, their studies concluded that: 1. Collaborative learning develops a community of peers which promotes student attendance and class participation. 2. Perspectives from a variety of learning sources were strongly influential on students, that is, beyond the one teacher as expert and only deliverer of knowledge. 3. Student academic performance was greater in collaborative learning settings, and students viewed the learning differently. Students created and shared new knowledge rather than individually memorizing and reciting it for the teacher only.

The continuing value of a learning community is in its emphasis on collaboration, "learning is better together" (Tinto, 2003, p. 2). Collaboration ensures a practical value because students come together and more learning is shared. Presumably, there is also a suggestion from Tinto (2003) that collaboration is 'better' because learning becomes enjoyable. The purpose of a learning community is to focus not just on the 'me', though, but on what the learning is giving to all collaborators, "a sense of shared purpose" (Demaris \& Kritsonis, 2008, p.2). This value is succinctly pinpointed by Geitner and Ditzhazy (1994) in the title Community: Engaging Individualism and Collegiality in Pursuit of Shared Purpose. Learning can be considered a collaborative enterprise, as individuals are engaged together for that common purpose. Thus collaboration is an important facet of a learning community.

The formal model of learning community is beyond what the author attempted in this international setting. It was rather the culture of the learning community model that was adopted; a culture of collaboration and connection. Hence, the author here uses the term 'learning community' without capital letters to distinguish it from the national Learning Community movement in the United States.

As of March 10, 2010, 284 Learning Communities were listed in the National Learning Community Directory (Washington Center, 2010). Recognition of the value of learning community in this wider definition helps practitioners to consider how such a culture can be introduced into their own classroom context.

\section{Learning Community - Value}

Roth and Lee (2006) trace the idea of learning communities back to Cognition in Practice (Lave, 1988) and Situated Learning (Lave \& Wenger, 1991, p. 27). Roth and Lee (2006) maintain that "communities at large .... are characterized by common ways of doing things," and the community defines the common way, rather than there being teacher-imposed rules ( $p .30)$. A value here is that students become self-directed learners, moving away from passively waiting to be told when and how to do something. Wenger (1998) used the term "communities of practice" to describe those environments where educators (as lifelong learners) learn about their own practice. A community of practice is a learning community, formed where 
community members become connected through what they do and through what they learn together. It is about mutual engagement in similar activities, which can be for work or for study; a defining element is that there must be a joint enterprise. The value of mutual support, joint enterprise, and communal resources within the setting of a community of practice also fits within the setting of learning communities.

Colleagues in a community of practice share their learning about teaching methodology, reflecting on the practice together, and thus opening all their reflection and practice to public gaze. Just as students in a learning community will share and reflect on their learning, as they too open themselves up to the gaze of their classmates. Foucault's (1994) notion of "gaze" in organizations construes that control is enforced by such surveillance (Arac, 1988; Boje \& Dennehy, April, 2000, p. 17). The gaze is directed onto everything and everybody where all activity is subject to such surveillance. Surveillance is thus positively enabled as students are expected to provide feedback to each other through peer review in a learning community (Bielaczyc \& Collins, 1999, p. 6). A value is gained through such surveillance, as students offer constructive criticism, and in turn receive valuable feedback from their classmates.

Dodge and Kendall (2004) believe learning communities have a value in enhancing future employability, as they

"foster workforce skills and encourage problem-solving skills" (p. 150). In a learning community, both individual and group activities take place, both can help with enforcing skills useful in the workplace (Bielaczyc \& Collins, 1999, p. 4). In the workplace, individuals are expected to work, sometimes alone and sometimes in groups, but in the end their contribution comes

Colleagues in a community of practice share their learning about teaching methodology, reflecting on the practice together, and thus opening all their reflection and practice to public gaze.

together for the benefit of the organization. Furthermore, other work skills, e.g., motivation and self-regulation (Dodge \& Kendall, 2004, citing Stefanou \& SalisburyGlennon, 2001) are fostered in a learning community. Motivation is enhanced as the individual's contribution is valued by all in a group because it contributes to task fulfillment. Self-regulation skills are learned as the individual keeps within the task parameters agreed to by group members. The learning of such skills as problemsolving, motivation, and self-regulation "ultimately serve[s] students well when they enter the workforce and seek leadership positions" (Dodge \& Kendall, 2004, p. 150). Another valued workplace skill to develop in a learning community is that of teamwork; specifically, learning communities concentrate on the sum of all members' learning, and what that contributes to the improvement in an individual's learning. A team is synergistic or greater than the sum of its parts: "teamworking is achieving the more successful completion of a task by working together, than the separate individuals would have done by working alone" (Leith, 1995, p. 802). Bielaczyc and Collins (1999, citing Scardamlia \& Bereiter, 1994, p.2) propose that members of a community achieve individual understanding through collective effort. In a learning community approach, by teaching how to share knowledge and how to learn from each other, educators ensure that students possess workplace skills of value for gaining and staying in employment.

\section{Learning Community - Stages}

The following stages reveal how this learning community addressed the learning needs of students through a classroom project to explore leadership in the region. 
Stage 1) Introduction of the Learning Community

For the student population in this article, each class contains a diversity of learners because the student body is composed of a great many nationalities. Evidence of this can be found in the university factbook; in spring 2010, there were 80 different nationalities studying at the university (AUS, 2010b). Different nationalities may have diverse positions on what college learning is about: rote learning versus experiential; some see teacher as expert, others value teacher as guide; individual competiveness for grades as opposed to group collaboration. So many different nationalities in the classroom bring the benefit of diversity and varying perspectives about college level learning, and thereby creates the need for a shared culture to bring these learners together. To Roth and Lee (2006), shared culture has a great deal to do with forming a community, a point that is of particular relevance to a learning community in an international setting because of the innate student diversity. The learning culture embedded in a learning community is the place for students of many nationalities to create, share, and build knowledge, through connection and collaboration.

A learning community needs to possess an identity, a sense of "who we are" (Bielaczyc \& Collins, 1999). Creating a learning community thus starts with a vision initially articulated by the teacher, a vision that students will build the community through the work they do. Benefits of the learning community approach are explained to students, before the teacher shows what is tangibly offered by way of current resources. A community of practice is based on communal resources, resources that are available to all (Wenger, 1998, p.2). The concept of a learning community has to be explained to students in small stages though, as to spend a long time at one session talking about the concept can be to the detriment of a

The learning culture embedded in a learning community is the place for students of many nationalities to create, share, and build knowledge, through connection and collaboration.

learning community. A long time would be to spend a whole first class or even subsequent large percentages of class time talking about the learning community. That would cause a return to passive learning, teacher talk and student listen, over talk could lead to boredom, and the teacher taking up too much time away from the timetabled subject. In most classrooms, the teacher tends to direct the activities, "typically spending most of their time interacting with the better students" (Bielaczyc \& Collins, 1999, p. 5). The teachers' position in the learning community needs to be explained briefly, and often as one of facilitator, coach, support, resource finder. I recommend introducing the idea of learning community through a quick overview, $10 \%$ of time perhaps in the first week or two of classes.

The teacher is a 'model' for the learning community in each class period; pointing out shared resources; expressing satisfaction on what students have learned from each other, etc. These methods will benefit the students in their progress through a course by reinforcing the benefits of learning community, by signaling 'best practice', and by rearticulating the vision as the community develops. An effective strategy for introducing the learning community identity and culture is for the teacher to demonstrate or highlight examples of the learning community as it happens in the classroom. This could be through praising an incident of learning community in action, or through adding or pointing out a resource for students. In a learning community, learning how to learn better is important. In summary, in the learning community approach, the teacher organizes and facilitates activities with all students; visioning continues; direction is lessened by the teacher as student ownership takes over. 
Stage 2) Embedding the learning community environment

As a complementary environment to building a community in the F2F classroom, there is the supplement of an online learning community (Palloff \& Pratt, 1999). Often, teachers are in the situation of teaching two or more sections of the same subject, so the description of how learning was combined and transferred across sections in this learning approach may help colleagues. As two sections of students are studying the same course in this case but at different times, so they were able to share their knowledge across teaching sections in this learning community. Without the idea of a community being introduced, Section i (9:30 a.m.) would have no access to knowledge from students in Section ii (2 p.m.) or vice versa. Different sections in time shared work about leaders and leadership via the Learning Management System known as Ilearn, a customized version of Blackboard. A learning management system (e.g., Blackboard) is essential, but a teacher does not need to be a technology expert to set this up for student access to an asynchronous community. It is hoped that following a similar strategy for readers of this article would enhance teaching and learning for them across sections.

An electronic medium makes other opportunities for community possible; it can extend rather than replace the F2F community. Knights (1997, citing Barglow, 1994, pp.183-184) however, suggest there is a fallacy in the idea that electronic media will lead us to a wider community (global village) because it represents "the construction of a network of tunnel visions: a world totally compartmentalized along lines of social class and professional specialization" ( $p$. 13). Such warnings about compartmentalization through technology make teaching through a learning community

An electronic medium makes other opportunities for community possible; it can extend rather than replace the F2F community.

of even greater importance. In a blended classroom experience, demonstrating how electronic media can add to and enhance learning through collaboration sends a message to community members (students) of how technology can be utilized for a more positive learning culture. There is no need to make judgment as to whether a $\mathrm{F} 2 \mathrm{~F}$ learning community or online learning community or blended community is best; they are all available for effective teaching and learning to take place. As a teacher it is worth recognizing that the answer to the question of the best way to teach is not the electronic media, but in using any available environment to build relationships between international students.

It is relationships that form a community, so a variety of student-student and student-teacher relationships can be nurtured by a variety of teaching environments (Kurucz, 2006). Students have their own views on forming relationships, and capturing such a variety of views is desirable. Student to student relationships are nourished as they share work with all students in discussion, in writing, in group work. The student-teacher relationship turns from director of learning to facilitator of learning, seen and heard physically in the F2F classroom and virtually online. Thus, F2F plus online teaching environments in a blended approach, bring out and enhance the effectiveness of relationship building through the work that students accomplish. The community builds as the relationships change and flourish. An environment is best where students are brought together rather than kept apart in a course, so that learning forms a relationship between students. The relationship increases the resources available to students, as now they also have each other as a resource.

The online environment becomes a repository of resources such as stored course presentations and materials for each class. Announcements and schedules in 
the electronic setting keep the students informed as to what is going on in the learning community. Until students are used to accessing the online area before, during, and after classes, email alerts can trigger a visit. Students are supposedly used to accessing such social networking sites as Facebook on a regular basis and without prompting, so it is feasible to consider that, with repetition, accessing the online learning community becomes automatic. Duncan-Howell (2010, citing Bond, 2004; Cornu, 2004; Matei, 2005) discusses how the electronic media make it possible "for individuals to interact, learn and access knowledge and resources within a social space" (p.326). Tinto and Goodsell-Love (1993) write about the many voices of faculty being present as they team teach a cohort in the structure of the formal learning community. The presence of other faculty may not be possible without the formal learning community, but in a blended F2F and online learning community, other voices as a resource can be heard through external links accessed by students.

As its members become embedded in the community environment, so they connect with each other, and the learning culture builds. The connection of peoples' knowledge, one with each other, is symbolic of the building of a collective culture focused on learning. The culture is then nurtured as a diversity of expertise is valued, with members of the community working together through shared objectives (Bielaczyc \& Collins, 1999).

\section{Stage 3) Working together in the Learning Community}

To hear what was needed in this international setting, the teacher listened to the student voices pointing out that the course text lacked examples of international leadership, concentrated on Western leaders, and ignored Arab leaders. Gabelnick et al. (1990) and Taylor et al. (2003) confirm that learning communities are based on a common theme. A common theme of exploring leaders in the Middle East had naturally arisen to connect the students in this learning community. Gabelnick et al. (1990) have an appreciation of the sharing that happens in learning communities, "a vital sense of shared inquiry." The general inquiry that all students follow during this course for the semester is, What are the traits/abilities/characteristics of a leader? The course outcome is that a common theme of leadership in the Middle East is shared across sections, and more knowledge is gained about leadership traits of these leaders. The theme of leaders in a geographical setting could be followed by other teachers, while another theme could be to compare leadership traits across geographical locations.

Rather than each student separately choosing a leader and a leadership trait to study, they added their leader and trait to a list that was open to be viewed by all. This information was coordinated through the use of a wiki, which is a student-editable document held in the virtual community resources. The criteria included a specification that each leader had to be different. This activity helps to ensure that a range of leaders are studied, as previously students were apt to choose the same famous ones. Each student studying a different leader also avoids the concern over copying, as all work is seen by all members (teacher and students) in the learning community and thus the possibility of copying is avoided. A clear differentiation is made by the teacher between shared learning and copying another's' work. It is a fine line as to when to share, what to share, and when is sharing carried too far and remains somebody else's work. However, balance is attainable in a learning community because the gaze of all is on everybody's work. For the important aspect of academic honesty, a learning community helps students to learn how to use peer scrutiny as a resource to benefit their own work.

Then students share their justification of why they chose to study that particular leader. Each student posts a paragraph of justification within a blog. This 
enables the teacher to comment on their justification, and the students in turn to respond to that comment. Each student is then requested to peer review a posting through the 'comment' facility. Thus, each student has at least studied others' justifications and has practiced a peer review. This activity is in contrast to an individual student submitting a justification to a teacher who evaluates and returns it to student. In that approach, only one student benefits from comments, a one-toone feedback situation. However, in the learning community, there is a many-tomany relationship as many have contributed to a review and benefit from reviews of others.

Each student next adds their research work on their individual leader to a wiki. As all blogs and wikis are open to view, students are able to read about and find out what others are researching. Then each student can read what others have been working on, and also edit one another's work. Admittedly, the strange names for electronic learning tools, such as wiki and blog, are a distraction which can be a potential barrier to learning; also, some learners may still not be familiar with these writing tools. However, it is as well to make use of these technological supports for their practical advantages. I simply explained that a blog is a space in which to post a comment and receive comments from classmates and teacher, and a wiki is a word document that all students could contribute to and be able to edit. These international students appeared to know what to do, and they were advised to call on their classmates or teaching assistant for help if puzzled. A quick demonstration with a teaching assistant helped; I did not consider that explanations of the meanings of blog and wiki would help. It may be that readers would prefer to spend more time on demonstration in class, depending on their students' abilities.

Another page is added to the wiki-a list of references being used in their research. Students add to this, and in so doing build a class list of shared references. This activity helps students to practice the particular formatting of references (APA or other designated style). If a student posts a reference, then another student can use that as a model or edit mistakes. The drive for research skills as a learning outcome in undergraduate curricula makes this step applicable across subjects.

Each student then prepares and delivers a short oral summary (max 5 minutes)

\section{All students need to be involved in some way in the project, and the organization of the roles is a decision for the students themselves.} on their leader. Written notes are made on the information delivered, and questions are asked by other students at this oral summary. Some students choose to record this delivery. On an interesting note of how a learning community can help with accommodating cultural and gender issues; in the project described above, female Emirati students do not wish their image to appear, thus recording is optional. However, prior recording served as a way around an issue for a very religious male Emirati student unable to make eye contact with females (including his Western teacher) due to a sense of 'disrespect'. A win win situation for learners is in a learning community where their individual cultural needs can be met through choice in learning activity. Dodge and Kendall (2004) consider that a learning community, composed of multiple nationalities, adds learning about intercultural communication.

All students need to be involved in some way in the project, and the organization of the roles is a decision for the students themselves. Thus there is skills enrichment in the form of negotiation, leadership and team-building through partnership and team/group activities. Trust, of course, has to be built up, and certainly in the early days of a semester, students need to work with peers they feel comfortable with. Enabling students to choose their own partners/groups helps in the beginning. Then students must be gently moved from a known situation to the unknown to ensure they are exposed to others in the learning community. A way to 
progress out of a comfortable learning zone is required, and attention and encouragement to work with others is practical, emphasizing the value of this to the community. By choosing the members of their groups, planning their work, and working with other groups, students establish a consistent class document. The outcome is new knowledge, created by a community of learners.

The culmination of the sharing of knowledge lies in the final product. The various leadership studies, as written by individual students, became a series of case studies of Middle Eastern leaders. This was achieved through the students working together in groups. With the help of teaching assistants, a final edit was made to the wiki to produce a consistent document. Pride in work produced is more likely when others can read your work, and it is displayed for all to see. On that point, I said that I would eventually be displaying the final wiki on the World Wide Web for all to admire and learn from this work on Middle East leaders. Whereupon a teaching assistant demanded to be able to have another edit if she and her classmates' names were to be associated with the work! Laudable pride, but perhaps a lesson learned by the teacher that extra work can inadvertently be added by wanting to share worldwide. I imagine that students' pride in their work goes across international contexts, and suggest that teachers reading this article may want to bring that pride to the fore.

Without even realizing that they have

The value of a learning community of students is manifest in the trifold benefits of: (1) the creation of new knowledge, (2) the sharing of learning, and (3) the building of knowledge with others. been working on this, students have together begun a new book of case studies about leaders from their own local area. What is more, this book can be added to by future cohorts of students; it is a living document. There is an ambitious plan to make such a product over time build into a compendium of Middle East leaders--the ultimate perhaps in what a learning community can achieve i.e., sharing new knowledge globally.

\section{Learning Community - Reflection}

This reflection aims to inform classroom practices through bringing together the author's understanding and experiences of learning community. It is hoped to be of practical benefit in aiding readers' understanding of the value of learning community for teaching. The value of a learning community of students is manifest in the trifold benefits of: (1) the creation of new knowledge, (2) the sharing of learning, and (3) the building of knowledge with others.

Besides these major benefits of a learning community, there are a host of other considerations that add value to the classroom (virtual and physical). The rationale for the introduction of collaborative opportunities in the classroom has been extended here as the physical space of the F2F classroom; plus the online space has been used to allow a learning community to emerge, continue, and prosper. The value of extending learning beyond the set space and time of the physical classroom adds to the idea of the mobility of learning; anytime; anywhere. Students in the twenty-first century manifestly enjoy and practice mobility, remaining attached to their community of friends through PDAs, cell phones, e-mail, schedules, and social spaces. That enjoyment and practice of mobility can be extended to learning as it keeps the learner connected to class colleagues virtually. When a student leaves a physical classroom at the end of the teaching session, being still connected to a community of learners can sustain the engagement in learning until the next formal teaching session.

There is a tendency, a given perhaps in the standard business classroom of today, the textbook is to be covered during the semester. In fact, course text are 
published, divided up into about 15 chapters, a convenience allowing one chapter to be taught per week during the 15 week semester (Daft, 2008; Gibson et al., 2008). Thus, the goal becomes to cover all the topics, in the belief that the mission is to complete the book with all students studying and learning the same thing at approximately the same rate. There is a mentality that breadth of knowledge is superior to depth of learning in the classroom performance. A race develops to cover all the topics in the curriculum as students and teacher strive to keep up in learning the same thing (Bielaczyc \& Collins, 1999). In contrast, a learning community sustains inquiry and development of products over months' (Bielaczyc \& Collins, 1999). A learning community develops through the semester. It is built up and out of the work of the semester rather than being there from the beginning. It is an organic component of the teaching environment, rather than a set piece to be drawn from. As such, this can be difficult for students to appreciate who are used to teaching and learning being fixed and available just in time. Students are for the most part expectant of handouts and presentations, not to mention a course book being ready and waiting for them. There is a lot to be gained in continuing with those very useful resources. But also the idea of creating, sharing and building knowledge from within needs to be constantly reinforced. The community of learning will die if it is not constantly fed, so each classroom session needs to encourage the idea and practice of community.

It is essential that the principle of the learning community is captured and adopted, that there is a 'physical space or facility for an intellectually stimulating environment to emerge' (Brower \& Dettinger, 1998, p.16). The stimulation for the students here was that there were few case studies of leaders from the Middle East. Thus, students had a real life problem to tackle that they had recognized for themselves i.e. the lack of leadership material about local leaders. As the students addressed the issue, the collaborative project developed skills of research and critical thinking (Palloff \& Pratt, 1999, p. 1). The teacher facilitated the sharing of the individual findings about leaders and leadership traits amongst all students adding to their academic learning. The sharing was achieved in multiple

The community of learning will die if it is not constantly fed, so each classroom session needs to encourage the idea and practice of community.

ways through the physical and virtual environment, in a purposeful effort to embed learning about the various leaders. The intangible learning lies in the collaborative method of working, the support for each other, and the sharing of ideas. These intangible activities need constant guidance, support and reinforcement by the teacher to progress all students in the community. The learning community is not just about the delivery of assignments; it offers more intangible learning benefits than that

\section{Conclusion}

Brower \& Dettinger (1998) are concerned that learning communities will become "just another buzzword" in teaching and learning (p.15). Another buzzword that will be used and mismanaged, and thus learning community will lose its essence of healthy collaboration, shared resources and learning together. Gabelnick et al. (1990) write of Learning Communities: Creating Connections Among Students, Faculty, and Disciplines, i.e., learning communities are more than a buzzword, they are about deep connections. Unless teachers take seriously the responsibility of teaching how to learn, then an outcome could be students who armed with their degree go out, but away from further learning. Or the outcome could be, to return to the evidence of Tinto (2003), a failure to complete their degree. The environment of a learning community could be a positive step in the 
right direction for students to learn how to learn together. A macrovalue is that teaching and learning in a community setting acknowledges the idea and practicality of 'community' as a sustainable benefit; a value that on graduation, students can take with them to the workplace and social environment. In presenting this learning community in an international setting, the aim has been to bring out points of value for those teaching in other international and national contexts. I have described the key elements for a successful learning community, and through the case study here, readers may want to experiment with some of the tactics to expand their own teaching and their students' learning.

\section{References}

Arac, J. (Ed.). (1988). Foucault: Modern or postmodern? After Foucault, humanistic knowledge, postmodern challenges. New Brunswick.: Rutgers University Press.

American University of Sharjah (2010a). Mission and Goals. Accessed Feb. 2010 at

http://www.aus.edu/about/mission.p $\mathrm{hp}$

American University of Sharjah (2010b). Fast facts. Accessed Feb. 2010 at

http://www.aus.edu/ir/info.php

Bielaczyc, K. \& Collins, A. (1999). Learning communities in classrooms: A reconceptualization of educational practice. From C.M Reigeluth (Ed.). Instructional design theories and models. Vol. ii. Mahwah NJ: Lawrence Erlbaum Associates.

Bielaczyc, K., \& Collins, A. (1999). Learning communities in classrooms: A reconceptualization of educational practice. Retrieved March 12, 2010, from http://isites. harvard.edu/fs/docs/icb. topic541040.files/Bielaczyc\% 20and\% 20Collins-

Learning\% 20Communities\% 20in\% 20 Classrooms.pdf

Boje, D. M., \& Dennehy, R. (April, 2000). Managing in the postmodern world. Retrieved from

http://cbae.nmsu.edu/-dboje
Brower, A.M., \& Dettinger, K. (1998)

What is a learning community?

Towards a comprehensive model. About Campus. 3(5). 15-21.

Carroll, L. (2009). Alice's adventures in wonderland and through the looking glass. Oxford: Oxford University Press.

Daft, R. L. (2008). The leadership experience (4th ed.). Mason: SouthWestern.

Demaris, M.C. \& Kritsonis, W.A. (2008). The classroom: exploring its effects on student persistence and satisfaction. Focus on Colleges, Universities and Schools. (2)1).

Dodge, L. \& Kendall, M.E. (Fall, 2004). Learning communities. College Teaching. (52)4, 150-155.

Duncan Howell, J. (2010). Teachers making connections: Online communities as a source of professional learning. British Journal of Educational Technology. 41(2), 324-340.

Foucault, M. (1994). The birth of the clinic: An archaeology of medical perception. New York: Vintage Books.

Gabelnick, F., MacGregor, J . Matthews, R. S., \& Smith, B.L (1990). Learning communities: Creating connections among students, faculty, and disciplines. No. 41. San Francisco: Jossey-Bass. 
Geitner B. \& Ditzhazy, H (2008). Shaping departmental community: Engaging individualism and collegiality in pursuit of shared purpose. ERIC ED379782. Accessed March 10, 2010 at

http://www.eric.ed.gov/ERI CWebPort al/custom/portlets/recordDetails/deta ilmini.jsp?_nfpb=true\&_\&ERICExtSea rch Search Value $0=E \bar{D} 379782 \& E R I C$ ExtS̄earch_Search̆Type_0=no\&accno $=\mathrm{ED} 379782$

Gibson, J. L., Ivancevich, J.M., Donnelly, J.H. Jr., \& Konopaske, R. (2009). Organizations Behavior, structure, processes (13th ed.). Boston: McGraw Hill.

Kellog, K. (1999). Learning communities. ERIC Digest.

(ED430512). Retrieved March 11, 2010 from ERIC database: http://eric.ed.gov/ERI CWebPortal/rec ordDetail?accno=ED430512

Knights, D. (1997). Organization theory in the age of deconstruction: dualism, gender and postmodernism revisited. Organization Studies.

18(1), 1-19. DOI:

$10.1177 / 017084069701800102$

Kurucz, P. (2006). How to teach international students: A practical teaching guide for universities and colleges. Victoria: Success Orientations Publishing.

Lave, J., \& Wenger, E. (1991). Situated learning: Legitimate peripheral participation. New York: Cambridge University Press.

Leith, G. (1995). Teamworking. Crainer S, (ed.). Financial Times handbook of management, the state of the art. London: Pitman Publishing.

Palloff, R. M., \& Pratt, K. (1999). Building learning communities in cyberspace: Effective strategies for the online classroom. San Francisco: J ossey Bass.
Palloff, R.M. \& Pratt, K. (1999). Building Learning Communities in Cyberspace "Effective strategies for the online classroom". Accessed March 10, 2010 at http://macqunilearners. pbworks.com /f/Building+Learning+Communities + I $\mathrm{n}+$ Cyberspace .doc

MDRC (2010). Learning Communities Demonstration. Policy framework. MDRC. Retrieved March 10, 2010 from

http://www.mdrc.org/project_31_76. html

Roth, W.M. \& Lee, Y.J. (2006).

Contradictions in theorising and implementing communities in education. Educational Research Review, 1(1), 27-40.

Smith, B.L. (Fall, 2001). Challenge of Learning Communities as a Growing National Movement. Peer Review. 4(1). Retrieved September 22, 2009, from

http://www.aacu.org/peerreview /pr$\mathrm{fa} 01 / \mathrm{pr}$-fa01feature1.cfm.

Taylor, K., Moore, W.S., MacGregor, J., \& Lindblad, J. (2003). Learning community research and assessment: What we know now. Executive Summary. Washington Center for Improving Higher Education. Retrieved March 11, 2010 from

http://www. evergreen.edu/washcent er/resources/upload/Pages_from_Im pactLC.pdf.

Tinto, V., \& Goodsell-Love, A. (1993). Building community. Liberal

Education, 79(4), 16.

Tinto, V. (2003). Learning better together: The impact of learning communities on student success. In Promoting Student Success in College. Higher Education Monograph Series (pp. 1-8). Syracuse, NY: Syracuse University. Retrieved March 11,2010 from

http://faculty.soe.syr.edu/vtinto/Files / Learning\% 20Better\% 20Together.pdf 
Washington Center for improving the quality of undergraduate education. (2010). National Learning

Communities Directory. Accessed

March 10, 2010 at

http://www. evergreen.edu/washcent er/Directory.asp

Wenger, E. (1998). Communities of practice: learning, meaning, and identity. Cambridge: Cambridge University Press.
Wenger, E. (1998). Communities of practice: Learning as a social system. [Published in the "Systems Thinker," June 1998]. Retrieved March, 11, 2010 from http://www.open.ac.uk/ldc08/sites/w ww.open.ac.uk. Idc08/files/Learningas asocialsystem.pdf

Linzi Kemp is Assistant Professor with the School of Business and Management, American University of Sharjah, United Arab Emirates (UAE) where she teaches leadership and organizational behavior. She was previously Faculty Associate, Empire State College, State University of New York, teaching and mentoring students in the Centers for Distance Learning and International Programs. Originally from the UK, Linzi has worked there in private and public organizations within education, retail and the NHS. Previous educational experience has been international, including ten years in the UAE, Kingdom of Saudi Arabia and the People's Republic of China. 